\title{
EVALUASI AKTIVITAS PEMUATAN LUMPUR PADA KEGIATAN PENAMBANGAN BATUBARA
}

\section{EVALUATION OF MUD LOADING IN COAL MINING ACTIVITY}

\author{
R. Saweni ${ }^{1}$, YS. Novianti2 ${ }^{*}$, KS. Putri ${ }^{3}$ \\ ${ }^{1-3}$ Program Studi Teknik Pertambangan, Fakultas Teknik, Universitas Lambung Mangkurat \\ Jl. Jenderal Achmad Yani KM 35,5 Banjarbaru, Kalimantan Selatan \\ e-mail: $\underline{\text { ruwaydahsaweni015@gmail.com, }}$ *2 yuniar@ulm.ac.id, ${ }^{3}$ karinashella@ulm.ac.id
}

\section{ABSTRAK}

Lumpur merupakan batuan sedimen berbutir halus yang memiliki kandungan utama berupa lempung dan lanau. Ukuran butirannya dapat mencapai $0.0625 \mathrm{~mm}$ (0.0025 inci). Pada umumnya proses pemindahan lumpur pada kegiatan penambangan dapat menggunakan slurry pump, namun untuk memanfaatkan ketersediaan alat mekanis perusahaan mencoba menggunakan metode load-haul-dump sebagai alternatif dalam melakukan pemindahan lumpur dari pit penambangannnya. Sehingga diharapkan kegiatan ini dapat membantu kegiatan pemindahan lumpur dan dapat bekerja dengan efektif dan ekonomis untuk dapat dipertimbangkan keberlanjutannya. Oleh karena itu, penelitian ini bertujuan untuk menganalisis kegiatan aktual di lapangan untuk mendapatkan keserasian penggunaan alat angkut dan alat gali muat. Adapun metodologi yang digunakan adalah menghitung dan membandingkan produktivitas dari masing-masing alat gali. Proses pemuatan lumpur menggunakan 2 cara yaitu, single digger dan double digger, peralatan yang digunakan berupa alat gali muat excavator Hitachi EX1200 dengan kapasitas $6.7 \mathrm{~m}^{3}$ dan alat angkut Komatsu HD465-7 dengan kapasitas 20m³. Dari hasil perhitungan produktivitas rata-rata aktual alat gali muat diperoleh yang terendah dengan metode double digger sebesar 288.10m³/jam pada tanggal 26 September 2019 dan yang tertinggi dengan metode single digger sebesar $495.80 \mathrm{~m}^{3} / \mathrm{jam}$ pada tanggal 28 September 2019. Faktor yang paling berpengaruh pada kegiatan loading lumpur dan pembuatan tanggul pada produktivitas adalah delay time sebesar -0.997 berdasarkan nilai korelasinya. Dengan berbagai hambatan yang terjadi sehingga dapat memperkecil waktu kerja efektif yang mengakibatkan efisiensi kerja dan produktivitas rendah.

Kata kunci : Gali-Muat-Angkut, Pemuatan Lumpur, Penggalian Tunggal dan Ganda

\section{ABSTRACT}

Mud is a fine-grained sedimentary rock whose main content is clay and silt. The grain size can be up to $0.0625 \mathrm{~mm}$ (0.0025 inches). As a rule, removing mud in mining activities can use a slurry pump, but the mining company tries to use the load-haul-dump method as an alternative in removing mud from its mining pits. Therefore, an actual technical analysis is needed to get the suitability of the digging and transportation tools. The mud loading process uses two methods: a single digger and a double digger. The equipment used is a Hitachi EX1200 excavator with a capacity of $6.7 \mathrm{~m}^{3}$ and a Komatsu HD465-7 haul-dump with a capacity of $20 \mathrm{~m}^{3}$. Calculation of digging and loading equipment productivity provide value lowest average actual excavator was on 26 September 2019 at $288.10 m^{3} /$ hour using the double digger method. The highest actual average productivity was 28 September 2019, amounting to $495.80 \mathrm{~m}^{3}$ / hour with a single digger method. In the mud loading activity, the most influencing factor on productivity based on the correlation value is the delay time that is -0.997. Various obstacles occur to minimize effective working time, which causes work efficiency and low productivity.

Keywords : Load-Haul-Dump, Mud Loading, Single And Double Digger 


\section{Jurnal Pertambangan}

\section{PENDAHULUAN}

Metode pemindahan lumpur yang digunakan pada tambang batubara PT Darma Henwa site Asam-Asam yaitu metode pemompaan slurry pump menggunakan pompa dan metode load-haul-dump menggunakan excavator backhoe dan dump truck. Kebanyakan tambang batubara menggunakan metode slurry pump untuk proses pemindahan lumpur. Salah satu contoh tambang menggunakan proses dewatering dan transportasi menggunakan pipa untuk membuang tailingnya [1]. PT Darma Henwa memvariasi pemindahan lumpurnya menggunakan metode loadhaul-dump. Pemindahan lumpur bertujuan untuk mengoptimalkan kegiatan penambangan batubara pada blok 18-21 yang berada di bawah material lumpur yang diperkirakan sebanyak $543.215 \mathrm{~m}^{3}$.

Lumpur sendiri terdiri dari lempung dan lanau. Lanau adalah tanah dengan ukuran berbutir halus yang terdiri dari bagian-bagian tanah mikroskopis yang mengembangkan kohesi atau plastisitas, sedangkan lempung adalah butiran yang lebih halus dari lanau, yang berupa gabungan butiran mineral kristalin yang bersifat mikroskopis [2]. Lumpur mempunyai kemampuan cenderung tidak melekat satu sama lain (tidak kohesif) dengan kekuatan yang kecil [3]. Penimbunan material lumpur cair harus diperhatikan baik secara lokasi maupun teknis penimbunannya. [4].

Produktivitas adalah parameter yang digunakan untuk mengetahui apakah alat tersebut sudah bekerja secara optimal atau tidak [5]. Untuk menghitung produktivitas backhoe, sebaiknya membatasi kondisi di lapangan. Perhitungan produktivitas backhoe sama seperti power shovel dimana jenis material mempengaruhinya [6]. cycle time (waktu edar), pola pemuatan, bucket fill factor, efisiensi kerja dan kondisi front penambangan adalah faktor-faktor yang mempengaruhi produktivitas pada alat gali muat [7].

Pada area produksi di Pit 4 Barat memiliki kendala yaitu terdapat material lumpur pada blok 18-21 sehingga dibutuhkan upaya untuk menangani lumpur tersebut agar kegiatan penambangan pada blok 18-21 dapat dioptimalkan. Adapun tujuan dari penelitian ini adalah menganalisis upaya penanganan lumpur, salah satunya berupa pemindahan lumpur menggunakan alat gali muat dan alat angkut yang harapannya dapat terlaksana secara efektif dan efisien sehingga dapat dipertimbangkan untuk keberlanjutan penggunaannya.

\section{METODE PENELITIAN}

Metode load-haul-dump yang digunakan PT Darma Henwa Site Asam-Asam untuk memindahkan lumpur dari Pit 4 Barat menuju disposal ialah pemuatan dengan metode single digger dan pemuatan dengan metode double digger. Metode single digger menggunakan 1 (satu) unit excavator yaitu Hitachi EX1200 untuk melakukan dua aktivitas yaitu pembuatan tanggul (vessel tanpa tailgate) dan pemuatan lumpur dimana material yang digunakan untuk pembuatan tanggul merupakan overburden dari luar Pit 4 Barat. Metode double digger menggunakan 2 (dua) unit excavator yaitu Komatsu PC400 untuk pembuatan tanggul [8] dan Hitachi EX1200 untuk pemuatan lumpur dimana material yang digunakan sebagai tanggul menggunakan overburden original di Pit 4 Barat.

Pada penelitian ini, variabel utama yang digunakan adalah cycle time dan delay time dari excavator Hitachi EX1200. Data cycle time alat gali muat yang diambil terdiri dari empat bagian waktu, antara lain waktu penggalian (digging time), waktu ayun bermuatan (swing time loaded), waktu pemumpahan (dumping time), dan waktu ayun kosong (swing time empty). Perhitungan produktivitas alat gali muat ( $\mathrm{Q}$ dalam $\mathrm{m}^{3} / \mathrm{jam}$ ) pada penelitian ini menggunakan persamaan 1 [9]:

$Q=\frac{3600}{C_{t}} \times q_{1} \times B F F \times E f f$

Berdasar pada persamaan 1, selain data cycle time $\left(\mathrm{C}_{\mathrm{t}}\right.$ dalam detik) juga digunakan data kapasitas bucket $\left(\mathrm{q}_{1}\right)$ sebesar $6.7 \mathrm{~m}^{3}$ yang berasal dari spesifikasi alat dan Bucket Fill Factor (BFF) dimana terbagi menjadi BFF pembuatan tanggul vessel dan BFF pemuatan lumpur. Sedangkan nilai efisiensi ( $\left.\mathrm{E}_{\mathrm{ff}}\right)$ bergantung dari data cycle time dan delay time.

Berdasarkan dari data yang diperoleh selanjutnya dilakukan analisis data berupa perbandingan produkvitas alat gali muat pada metode pemuatan single digger dan double digger, kemudian dilanjutkan dengan mengklasifikasikan faktor-faktor yang mempengaruhi produktivitas alat gali muat pada masing- masing metode pemuatan dan yang terakhir adalah memberikan rekomendasi perbaikan masing-masing metode pemuatan untuk meningkatkan produktivitas alat gali muat.

\section{HASIL DAN PEMBAHASAN}

Komponen cycle time yang dihasilkan pada pemuatan metode single digger berbeda dengan metode double digger (lihat gambar 1). Dapat dilihat bahwa pada tanggal 26 September menunjukkan cycle time rata-rata terlama dan hanya terdapat satu (1) komponen cycle time yaitu pemuatan lumpur karena pada tanggal tersebut aktivitas pemuatan lumpur menggunakan metode double digger dimana aktivitas pembuatan tanggul dilakukan oleh excavator lain (Komatsu PC400). Sedangkan pada tanggal yang lain metode pemuatan lumpur menggunakan metode single digger sehingga terdapat 


\section{Jurnal Pertambangan}

dua komponen cycle time yaitu cycle time pembuatan tanggul dan cycle time pemuatan lumpur.

Cycle time dipengaruhi oleh pola pemuatan yang menggunakan metode pola pemuatan top loading dan bottom loading, dan berdasarkan data cycle time pada gambar 1 pola pemuatan dengan menggunakan metode top loading berada pada tanggal 20, 24, 27 dan 28 September dan menunjukkan bahwa nilai cycle time pada pola pemuatan top loading lebih baik dibandingkan dengan nilai cycle time pola pemuatan bottom loading.

Material pada kegiatan loading lumpur terbagi menjadi dua jenis material yaitu material yang akan dipindahkan yaitu lumpur (Gambar 2) dan material tanah pasir untuk pembuatan tanggul (Gambar 3). Berdasarkan hasil pengamatan diperoleh nilai BFF untuk material tanah pasir sebesar 0.95 dan untuk material lumpur sebesar $1[10]$.

Efisiensi kerja dihasilkan dari perbandingan antara waktu kerja efektif terhadap waktu kerja yang tersedia. Waktu kerja efektif di sini diklasifikasikan sebagai waktu yang benar-benar digunakan untuk kegiatan produksi dalam hal ini adalah cycle time. Sedangkan waktu tersedia merupakan jumlah dari cycle time dan delay time.

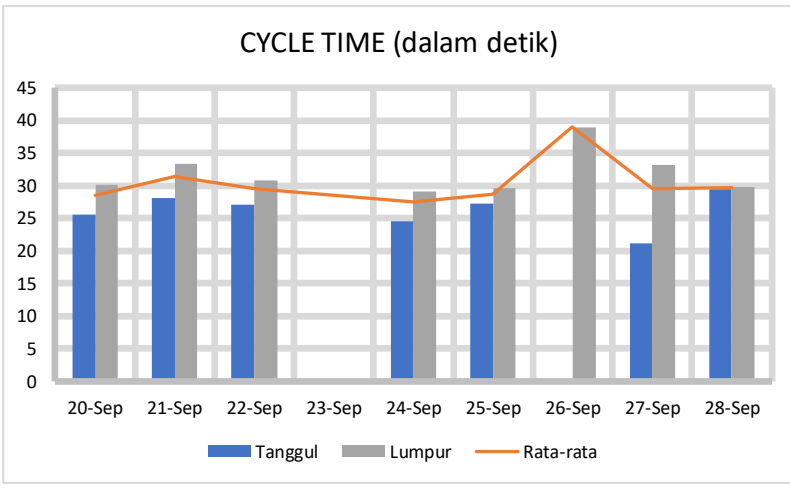

Gambar 1. Cycle time Excavator Hitachi EX1200

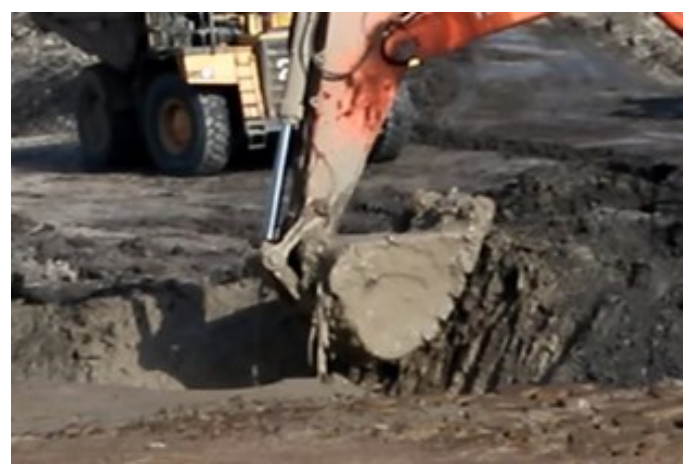

Gambar 2. Bucket fill factor untuk material lumpur

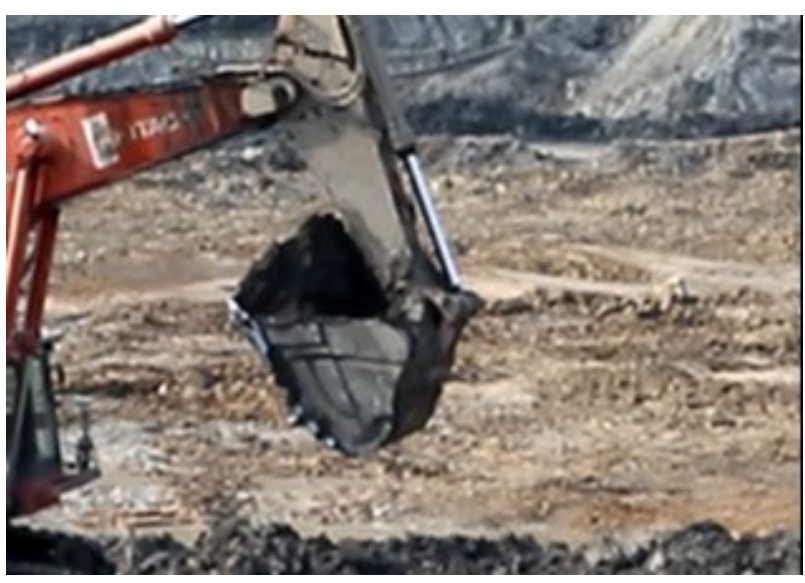

Gambar 3. Bucket fill factor untuk material tanggul

EFISIENSI KERJA

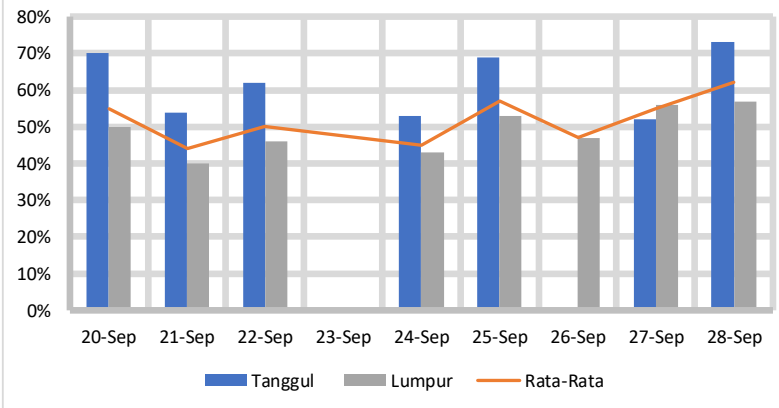

Gambar 4. Efisiensi kerja Excavator Hitachi EX1200

Berdasarkan Gambar 4 dapat dilihat seperti halnya cycle time, efisiensi kerja pun dibagi menjadi dua komponen yaitu efisiensi kerja pembuatan tanggul dan efisiensi pemuatan lumpur, dengan efisiensi tertinggi pada pembuatan tanggul adalah sebesar $73 \%$ dan terendah sebesar 52\% sedangkan untuk efisiensi tertinggi pemuatan lumpur adalah sebesar $62 \%$ dan terendah sebesar 44\%. Khusus pada tanggal 26 September yang hanya terdapat efisiensi kerja pemuatan lumpur karena metode yang digunakan adalah double digger. Bervariasinya nilai efisiensi ini banyak dipengaruhi oleh waktu delay yang diakibatkan beberapa faktor antara lain perbaikan loading point dan posisi bucket alat muat yang menggantung dikarenakan menunggu pergantian posisi alat angkut.

Produktivitas menjadi parameter yang digunakan untuk menilai performa kerja suatu alat pemindahan tanah mekanis. Berdasarkan Tabel 1 dapat dilihat bahwa metode double digger memiliki produktivitas rata-rata sebesar $288.10 \mathrm{~m}^{3} / \mathrm{jam}$ dan lebih rendah dibandingkan dengan metode pemuatan single digger. Sedangkan pada metode pemuatan single digger, produktivitas rata-rata tertinggi sebesar $495.80 \mathrm{~m}^{3} / \mathrm{jam}$ pada tanggal 28 


\section{Jurnal Pertambangan}

September 2019 dengan pola pemuatan top loading serta produktivitas rata-rata terendah sebesar $331.20 \mathrm{~m}^{3} / \mathrm{jam}$ pada tanggal 21 september 2019 dengan pola pemuatan bottom loading (Gambar 5). Dari hasil perhitungan tersebut didapatkan beberapa faktor yang mempengaruhi produktivitas antara lain cycle time (pola pemuatan dan sudut swing), efisiensi kerja, dan kondisi loading point.

Variabel yang memiliki data bersifat fluktuatif dalam perhitungan produktivitas adalah cycle time dan delay time. Matrik pada Tabel 2, 3 dan 4 menunjukkan faktor yang mempengaruhi produktivitas Excavator Hitachi EX1200 berdasarkan nilai korelasi.

Berdasarkan perbandingan nilai korelasi yang dihasilkan dalam aktivitas pembuatan tanggul pada vessel dump truck (Tabel 2), faktor yang memiliki pengaruh paling besar terhadap produktivitas adalah delay time dengan nilai $r$ yaitu $-0,861$.

Tanda negatif pada nilai korelasi menunjukan arah korelasi yang berbanding terbalik yaitu semakin lama delay time yang terjadi maka semakin rendah produktivitas begitu pula sebaliknya. Sedangkan cycle time merupakan variabel produktivitas yang pengaruhnya sangat kecil dengan nilai r yaitu -0.205 .

Tabel 1. Produktivitas aktual Excavator Hitachi EX1200

\begin{tabular}{|c|c|c|c|l|l|}
\hline \multirow{2}{*}{ Tgl } & \multicolumn{3}{|c|}{ Produktivitas $\left(\mathrm{m}^{3} / \mathrm{jam}\right)$} & $\begin{array}{c}\text { Pola } \\
\text { Pemuatan }\end{array}$ & $\begin{array}{l}\text { Metode } \\
\text { Pemuatan }\end{array}$ \\
\cline { 2 - 4 } 20-Sep & 621.92 & 402.86 & 460.40 & $\begin{array}{l}\text { Top } \\
\text { Loading }\end{array}$ & $\begin{array}{l}\text { Single } \\
\text { Digger }\end{array}$ \\
\hline 21-Sep & 440.50 & 292.78 & 331.20 & $\begin{array}{l}\text { Bottom } \\
\text { Loading }\end{array}$ & $\begin{array}{l}\text { Single } \\
\text { Digger }\end{array}$ \\
\hline 22-Sep & 521.39 & 359.56 & 397.76 & $\begin{array}{l}\text { Bottom } \\
\text { Loading }\end{array}$ & $\begin{array}{l}\text { Single } \\
\text { Digger }\end{array}$ \\
\hline 24-Sep & 496.33 & 353.02 & 391.62 & $\begin{array}{l}\text { Bottom } \\
\text { Loading }\end{array}$ & $\begin{array}{l}\text { Single } \\
\text { Digger }\end{array}$ \\
\hline 25-Sep & 575.51 & 429.86 & 473.36 & $\begin{array}{l}\text { Top } \\
\text { Loading }\end{array}$ & $\begin{array}{l}\text { Single } \\
\text { Digger }\end{array}$ \\
\hline 26-Sep & 0.00 & 288.10 & 288.10 & $\begin{array}{l}\text { Top } \\
\text { Loading }\end{array}$ & $\begin{array}{l}\text { Double } \\
\text { Digger }\end{array}$ \\
\hline 27-Sep & 569.29 & 405.60 & 442.20 & $\begin{array}{l}\text { Top } \\
\text { Loading }\end{array}$ & $\begin{array}{l}\text { Single } \\
\text { Digger }\end{array}$ \\
\hline 28-Sep & 567.88 & 465.07 & 495.80 & $\begin{array}{l}\text { Top } \\
\text { Loading }\end{array}$ & $\begin{array}{l}\text { Single } \\
\text { Digger }\end{array}$ \\
\hline
\end{tabular}

Tabel 2. Nilai korelasi (r) produktivitas pembuatan tanggul

\begin{tabular}{|l|r|r|r|}
\hline & $C T$ & Delay & Produktivitas \\
\hline CT & 1 & & \\
\hline Delay & -0.310038547 & 1 & \\
\hline Produktivitas & -0.205383309 & $\mathbf{- 0 . 8 6 1 3 0 4 9 5 6}$ & 1 \\
\hline
\end{tabular}

Tabel 3. Nilai korelasi (r) produktivitas pemuatan lumpur

\begin{tabular}{|l|r|r|r|}
\hline & \multicolumn{1}{|c|}{$C T$} & Delay & Produktivitas \\
\hline CT & 1 & & \\
\hline Delay & 0.542381713 & $\mathbf{1}$ & 1 \\
\hline Produktivitas & -0.674954005 & $\mathbf{- 0 . 9 7 7 2 5 7 6 4}$ & \\
\hline
\end{tabular}

Tabel 4. Nilai korelasi (r) produktivitas rata-rata

\begin{tabular}{|l|r|r|r|}
\hline & \multicolumn{1}{|c|}{ CT } & \multicolumn{1}{|c|}{ Delay } & Produktivitas \\
\hline CT & 1 & & \\
\hline Delay & 0.715583705 & 1 & \\
\hline Produktivitas & -0.744477321 & $\mathbf{- 0 . 9 9 7 0 1 3 9 6 4}$ & 1 \\
\hline
\end{tabular}

PRODUKTIVITAS (dalam $\mathrm{m}^{3} / \mathrm{jam}$ )

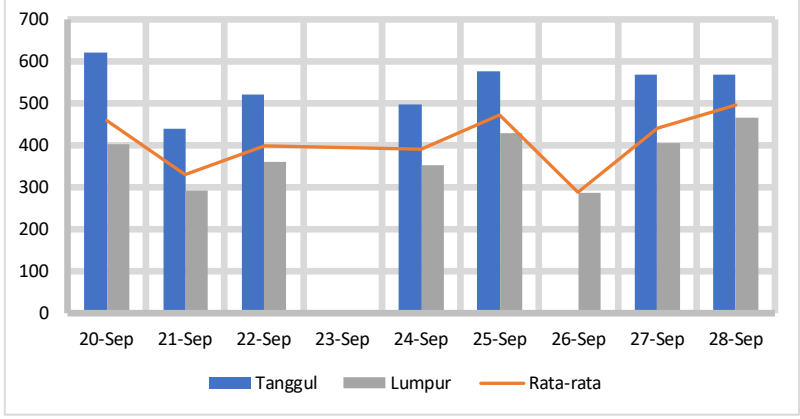

Gambar 5. Produktivitas aktual excavator hitachi EX1200

Berdasarkan perbandingan nilai korelasi (r) pada produktivitas rata-rata (Tabel 4), faktor yang memiliki pengaruh paling besar terhadap produktivitas dengan nilai r yaitu $-0,997$ adalah delay time sedangkan cycle time merupakan faktor produktivitas yang pengaruhnya lebih kecil dengan nilai $\mathrm{r}=-0.744$.

\section{Rekomendasi Upaya Perbaikan}

Aktivitas pemindahan lumpur di Pit 4 Barat oleh PT Darma Henwa site Asam Asam dengan dua metode pemuatan menghasilkan produktivitas Excavator Hitachi EX1200 yang berbeda dimana produktivitas metode single digger lebih tinggi dibandingkan produktivitas metode double digger baik dengan pola top loading maupun pola bottom loading. Sehingga rekomendasi metode pemuatan lumpur yang dipilih adalah menggunakan metode single digger.

Berdasarkan nilai korelasi pada aktivitas pembuatan tanggul dan pemuatan lumpur yang menunjukkan bahwa delay time merupakan variabel yang paling berpengaruh terhadap produktivitas, sehingga upaya-upaya untuk mengoptimalkan produktivitas pada metode single digger akan berfokus pada pegurangan delay time. Kondisi-kondisi yang sering terjadi sehingga excavator mengalami delay time adalah hambatan suplai material untuk pembuatan tanggul dan menunggu proses manuver dump truck di loading point.

Untuk mengurangi hambatan suplai material dan meningkatkan waktu kerja efektif pada alat gali muat sebaiknya memaksimalkan kerja untuk alat support bulldozer dengan mengerjakan general loading point. 
Sedangkan untuk memudahkan manuver alat angkut maka harus memperlebar loading point sesuai standar. Dari hasil perhitungan diketahui lebar loading point standar untuk alat angkut HD 4654-7 sebesar 20.51 meter. Selain memperlebar loading point sesuai ukuran standar, loading point juga harus dilakukan perawatan berkala agar tidak bergelombang sehingga dapat memperlancar pergerakan alat angkut.

\section{KESIMPULAN}

Berdasar pada pembahasan yang telah diuraikan, maka dapat diambil kesimpulan bahwa penanganan lumpur pada Pit 4 Barat dapat diatasi dengan memindahkan lumpur ke luar pit menggunakan metode load-hauldump. Namun dari hasil perbandingan diperoleh bahwa metode single digger lebih produktif dibandingkan dengan metode pemuatan double digger baik menggunakan pola pemuatan top loading maupun bottom loading. Sedangkan variabel yang paling berpengaruh pada produktivitas Excavator Hitachi EX1200 berdasarkan nilai korelasi adalah delay time. Dengan memindahkan lumpur pada area blok 18-21 di Pit 4 Barat, kegiatan penambangan batubara dapat kembali bekerja secara optimal.

\section{DAFTAR PUSTAKA}

[1] Crawford, J., \& Bessett, N. (2019). Development of centrifugal slurry pumps in tailings disposal and comparison with positive displacement pumps. In Proceedings of the 22nd International Conference on Paste, Thickened and Filtered Tailings (pp. 517530). Australian Centre for Geomechanics, Perth.

[2] Gunarti, A.S.S., (2014). Daya Dukung Tanah Lempung yang Distabilisasi dengan Spent Catalyst RCC 15 dan Kapur. Jurnal Teoritis dan Terapan Bidang Rekayasa Sipil 2 (1).

[3] Zaki, M. (2015). Kajian Teknis Pemindahan Lumpur di Area Penambagan Muara Tiga Besar Selatan PT. Bukit Asam (Persero) TBk. Skripsi, Universitas Syiah Kuala Darussalam. Banda Aceh.

[4] Afrianto, S., \& Azmi, C. N. (2020). Penimbunan Material Lumpur Cair Dengan Menggunakan Metode Sliding Pad. Prosiding Temu Profesi Tahunan PERHAPI, 1(1), 615-622.

[5] Firdaus, M.A., dkk. (2020) Evaluasi Produktivitas Alat Gali Muat Terhadap Pencapaian Target Produksi Overburden di PT Rimau Energy Mining, Site Desa Putut Tawuluh,
Kecamatan Dusun Timur, Kabupaten Barito Timur, Provinsi Kalimantan Tengah. Jurnal Himasapta 5(3).

[6] Suryadi, A., (2019), Analisis Pengaruh Efectitive Utilization terhadap Ketercapaian Produksi Batubara PT Semesta Centramas. Jurnal Geosapta 5 (1).

[7] Khair. A, (2019), Evaluasi Pencapaian Target Produktivitas Alat Gali Muat Dan Alat Angkut Pada Aktivitas Pemindahan Overburden Di Pit1 Blok15 Pt Rimau Energy Mining, Site Putut Tawuluh, Jurnal Himasapta 4 (1).

[8] Komatsu, (2013), "Specifications \& Application Handbook Edition 31", Komatsu, Japan.

[9] Indonesianto,Y., (2013), Pemindahan Tanah Mekanis, Jurusan Teknik Pertambangan UPN "Veteran", Yogyakarta.

[10] Caterpilar. (2019). Performance Handbook Edition 49. Caterpillar Inc. Peoria, Llionis, USA. 